Jourial of Chromatography, 181 (1980) $329-335$

Biomedical Applications

- Elsevier Scientifie Publishing Company, Amsterdam - Printed in The Netherlands

CHROMBIO. 489

\title{
PAIRED-ION HIGH-PERFORMANCE LIQUID CHROMATOGRAPHIC ASSAY FOR PLASMA CHOLINE
}

DOUGLAS N. BUCHANAN"t, FPANZ R. FUCEK and EDWARD F. DOMINO

Department of Pharmacology, Lafayette Clinic, 951 E. Lafayette, Detrait, Mich. 48207 (U.S.A.) and The University of Michigan, Ann Arbor, Mich. 48109 (U.S.A.)

(First received August 3rd, 1979 ; revised manuseript received November 11th, 1979)

\section{SUMMARY}

Choline was isolated from deproteinized plasma by cationexchange chromatography. Isolated choline ras directly converted to the 3,5-dinitrobenzoate derivative and was analyzed by paired-ion high-performance liquid chromatography with UV detection at $254 \mathrm{~nm}$. An internal standard, 3-hydroxy- $N, N, N$-trimethylpropanaminium iodide was used for quantitation of plasma choline.

Linearity was achieved from $1-500 \mathrm{nmole} / \mathrm{ml}$ with a reproducibility of $\pm 6 \%$. Plasma choline concentrations below 1 nmole/ml could not be accurately measured while plasma choline concentrations in the $\mu$ mole/ml range deviated from linearity.

\section{INTRODUCTION}

The quantitative analysis of choline in biological samples has been effected using a yeast culture [1], radioenzyme assays [2-5], a spectrophotometric assay [6], a polarographic assay [7], gas chromatographic assays $[8,9]$ and gas chromatographic - mass spectrometry assays [10-12].

Most of the procedures are highly esoteric and involve complicated and/or expensive instrumentation that are not normally found in clinical research laboratories. Gas chromatographs are readily accessible but the assays for choline involve either the pyrolysis of the quaternary salt [13] or the chemical demethylation of the quaternary salt with sodium benzenethiolate [8-11].

\footnotetext{
- Presented at the Waters Associates International Liquid Chromatography Symposium, October 11, 1979, Boston, Mass., U.S.A.

*Present address: Genetic Screening Unit, Hawthorn Center, 18471 Haggerty Road, Northville, Mich. 48167 , U.S.A.
} 
Pyrolysis and chemical demethylation oî esterified choline, i.e., acetylcholine or butanoylcholine $[8,9]$ have been reported $[14-16]$ to sause the cleavage of the ester moiety from choline thus potentially leading to erroneous results. In addition, the chemical demethylation of choline with sodium benzenethiolate is a long, involved, process that requires highly trained personnel. The current surge of interest in the use of high-performance liquid chromatography (HPLC) in elinical research laboratories prompted the development of a simple, pairedion HPLC assay for plasma choline.

Choline was isolated from deproteinized plasma by cation-exchange chromatography [9]. The isolated choline was directly converted to the 3,5-dinitrobenzoyl ester by treatment with 3,5-dinitrobenzoyl chloride in pyridine. The 3,5-dinitrobenzoate was analyzed by paired-ion HPLC. An internal standard, 3-hydroxy-N,N,N-trimethylpropanaminium iodide, was used for the quantitation of choline.

EXPERTMENTAL

\section{Chemicals}

Choline chloride, 98\%, purchased from Eastman (Rochester, N.Y., U.S.A.) was recrystallized twice from absolute ethanol-diethyl ether [17] . 3-Hydroxy$\mathrm{N}, \mathrm{N}$-dimethylaminopropane, iodomethane, sodium dodecyl sulfate and 3,5dinitrobenzoyl chloride were purchased from Aldrich (Milwaukee, Wisc., U.S.A.) and ware used without further purification.

\section{Solvents}

All solvents were distilled in glass grade purchased from Burdick and Jackson Labs. (Muskegon, Mich., U.S.A.). Deionized water was distilied from alkaline permanganate and was filtered through a $0.22-\mu \mathrm{m}$ Millipore filter before use.

\section{Equipment}

IR spectra were recorded on a Beckman IR 4240 spectrometer. UV spectra were recorded on a Beckman DB spectrometer. A Bioanalytical Systems LC-50 liquid chromatograph empioying two $\mu$ Bondapak $C_{18}$ (particle size $10 \mu \mathrm{m}$ ) analytical columns (30 cm $\times 4 \mathrm{~mm}$ I.D.) Waters Assoc., (Milford, Mass., U.S.A.) in tandem and an Altex 110 fixed wavelength (254 nm) ultraviolet detector were used for quantitative analysis. A chloride specific ion electrode (Cole-Parmer) was used for the determination of choline in the standard choline chloride solution.

\section{Preparation of 3-hydroxy-N,N,N-trimethylpropanaminium iodide}

To $10.0 \mathrm{~g}$ (97.1 mmole) of 3-hydroxy-N,N-dimethylaminopropane in $24 \mathrm{ml}$ of absolute ethanol were added $18.5 \mathrm{~g}$ (130.1 mmole) of iodomethane. Upon stirring at ambient temperature, a white precipitate formed. The mixture was filtered. The supernatant was cooled and cold absolute diethyl ether was added producing $\bar{a}$ white precipitate. The mixture was filtered. The combined precipitate was recrystallized from absolute ethanol-diethyl ether affording $23.7 \mathrm{~g}$ (100\%) of a white crystalline solid, m.p. 203-204 (literature [18] m.p. 201$202^{\circ}$ from absolute ethanol). 
The 3,5-dinitrobenzoate was prepared according to the procedure of McElvain [19] affording a golden solid, m.p. 172-174 (dec.) from absolute ethanol-diethyl ether: $\mathbb{I R}(\mathrm{KBr}) \cdot 3125,1740,1550,1354,1286,827,739$ and 725 $\mathrm{Cm}^{-1} . U V \mathrm{X}_{\max }^{\mathrm{H}_{2} \mathrm{O}}=230 \mathrm{~nm}\left(\epsilon=1.72 \cdot 10^{4}\right)$.

A single peak was observed in the HPLC chromatogram at $15 \mathrm{~min}$ using $5 \mathrm{mM}$ sodium dodecyl sulfate in $50 \%$ acetonitrile through the two $\mu$ Bondapak $C_{18}$ analytical columns in tandem at a flow-rate of $2 \mathrm{ml} / \mathrm{min}$.

Preparation of 2-(3,5-dinitrobenzoyl)-N,N,N-trimethylethanaminium chloride

The 3,5-dinitrobenzoate of choline chloride was prepared according to the procedure of McElvain [19] affording a pale yellow solid in $85 \%$ yield; m.p.

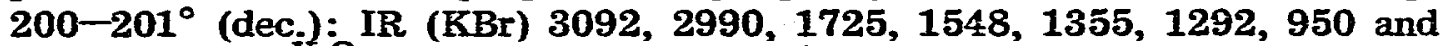
$730 \mathrm{~cm}^{-1}$. UV $\lambda_{\max }^{\mathrm{H}} \mathrm{O}=230 \mathrm{~nm}\left(\epsilon=9.48 \cdot 10^{3}\right)$.

A single peak was observed in the HPLC chromatogram at $13 \mathrm{~min}$ using $5 \mathrm{mM}$ dodecyl sulfate in $50 \%$ acetonitrile through the two $\mu$ Bondapak $\mathrm{C}_{18}$ analytical columns in series at $\mathrm{a}$ flow-rate of $2 \mathrm{ml} / \mathrm{min}$.

\section{Analytical procedures}

Standard curve preparation. To four sets of duplicate $0.25-\mathrm{ml}$ aliquots of Red Cross human plasma were added $25 \mu 1$ of $0.41 \mathrm{mM}$ 3-hydroxy-N,N,N-trimethylpropanaminium iodide (internal standard) and:

$A, 0 \mu \mathrm{l} ; \mathrm{B}, 10 \mu \mathrm{l} ; \mathrm{C}, 25 \mu \mathrm{l}$ and $\mathrm{D}, 50 \mu \mathrm{l}$ of $0.23 \mathrm{mM}$ choline chloride.

Sample preparation. To duplicate $0.25-\mathrm{ml}$ aliquots of plasma were added $25 \mu 1$ of internal standard $(0.41 \mathrm{mM})$. To each sample was added $0.75 \mathrm{ml}$ of ice cold $1 M$ formic acid-acetone to precipitate the protein. The samples were mixed and were centrifuged for $15 \mathrm{~min}$ at high speed in a benchtop centrifuge. The supernatant was decanted and was used for the analysis.

Ion-exchange chromatography [9]. Cation-exchange resin (AG 50W-X12), $300 \mathrm{mg}$ per sample, was allowed to sit overnight in $1 \mathrm{ml}$ of $0.1 \mathrm{M}$ ammonium acetate pH 4.0. Pasteur pipets, 5 in., were fitted with glass wool plugs and the presoaked ion-exchange resin was added to each column. The solvent was allowed to pass through the resin. Fach column was cleaned by the passage of $1 \mathrm{ml}$ of $2 \mathrm{M} \mathrm{NaCl}$ in $50 \%$ methanol through the resin and was activated by the passage of $1 \mathrm{ml}$ of $0.1 \mathrm{M}$ ammonium acetate, $\mathrm{pH} 4.0$ through the resin. The plasma supernatant was placed on the column. Each column was washed with $1 \mathrm{ml}$ of $0.1 \mathrm{M}$ ammonium acetate, $\mathrm{pH}$ 4.0. Choline and the internal standard were eluted from the resin by the passage of $1 \mathrm{ml}$ of $2 M \mathrm{NaCl}$ in $50 \%$ methanol, all liquid was forced out of the column by a rubber squeeze bulb.

Each sample was taken to dryness under a stream of nitrogen and kept under a vacuum for an hour. Choline and the internal standard were extracted from the salt residue by the addition of $1 \mathrm{ml}$ of dry acetonitrile. The sides of each sample tube were thoroughly scraped with the tip of a Pasteur pipet.

Each sample was mixed and centrifuged. The supernatant was removed and saved. This process was repeated with an additional $1-\mathrm{ml}$ aliquot of dry acetonitrile. The combined supernatant from each sample was taken to dryness under a stream of nitrogen.

Sample derivatization. To the residue from the evaporation of acetonitrile was added $0.30 \mathrm{ml}$ of a $21.7 \mathrm{mM}$ solution of 3,5-dinitrobenzoyl chloride in dry 
(KOH) pyridine (prepared immediately prior to use). The samples were heated for $1 \mathrm{~h}$ at $105^{\circ}$ in a hot sand bath. The pyridine was removed under a stream of nitrogen. The zesidue was first extracted with $0.30 \mathrm{ml}$ of glass distilled water and then with $0.20 \mathrm{ml}$ of glass distilled water. The combined aqueous extract was nittered through a 0.3- $\mu \mathrm{m}$ Millipore filter.

HPEC conditions. The filtered aqueous extract was placed onto two $\mu$ Bonda-

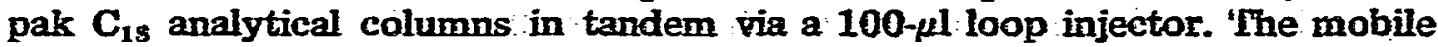
phase, $5 \mathrm{mM}$ scdium dodecyl sulfate and $0.1 \%$ acetic acid in $50 \%$ acetonitrile - was pumped at a flow-rate of $2-2.3 \mathrm{ml} / \mathrm{min}$. Detection was facilitated by a fixed wavelength $(254 \mathrm{~nm})$ UV detector. The retention time for dinitrobenzoyl (DNB)-choline was $13 \mathrm{~min}$ while the retention time for the DNB derivative of the internal standard was 15 min (Fig. 1).

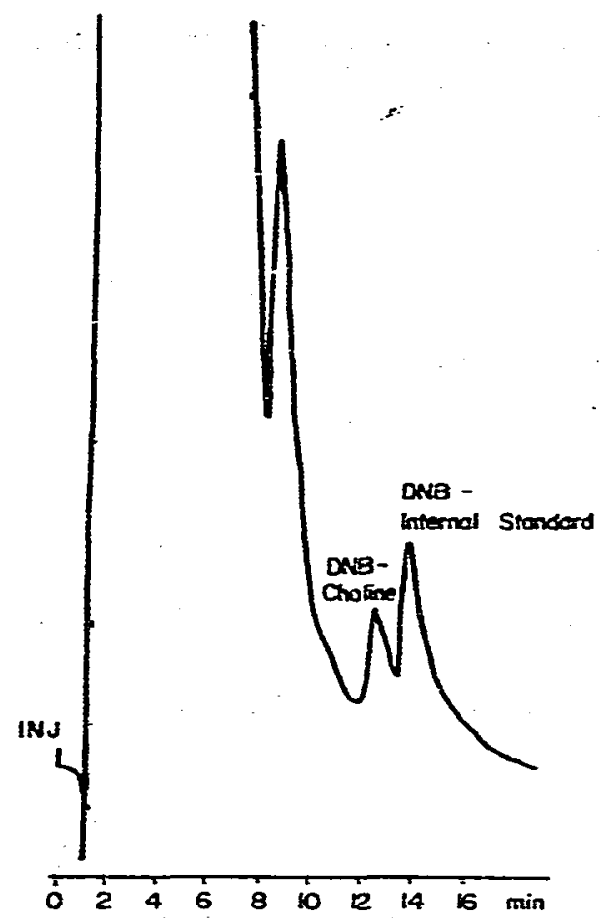

Fig. 1. HPLC chromatogram of human plasma choline (22 nmole/ml). Conditions: two $\mu$ Bondapak $C_{13}(10 \mu m)$ analytical columns in tandem; mobile phase, 5 m $M$ sodium dodecyl sulfate- $0.1 \%$ acetic acid-50\% acetonitrile; flow-rate, $2.0-2.3 \mathrm{ml} / \mathrm{min}$; detection wavelength $254 \mathrm{~nm}$. A level of $22 \mathrm{nmole} / \mathrm{ml}$ was assayed. DNB-choline and DNB-IS (DNB-3-hydroxy$\mathrm{N}, \mathrm{N}, \mathrm{N}$-trimethylpropaminum iodide) $(40 \mathrm{nmole} / \mathrm{ml})$ as the internal standard are shown.

\section{Calculations}

The method of standard addition was used to obtain the standard curve. The slope of the standard curve was calculated by linear regression analysis of choline concentration vs. peak height choline/peak height intemal standand ratio. The slope of the standard curve was used as the working curve to calculate the choline concentration in the samples. The average value of two duplicate analyses was used to determine the choline concentration in each sample. Reproducibility was $\pm 6 \%$ of the mean. Linearity was achieved from $1-500$ 
nmole/ml. Below $1 \mathrm{nmole} / \mathrm{ml}$, the choline concentration could not be accurately determined. Above $500 \mathrm{nmole} / \mathrm{ml}$, the choline concentration deviated negatively from linearity.

\section{RESULTS}

Choline was isolated from plasma by cation-exchange chromatography following the procedure of Zahniser et al. [9]. It was found that $300 \mathrm{mg}$ of AG $50 W-X 12$ resin per column quantitatively retained choline and the internal standard. Complete elution of these compounds from the column was effected by the passage of $1.0 \mathrm{ml}$ of $2 \mathrm{M} \mathrm{NaCl}$ in $50 \%$ methanol. Precipitation of plasma protein with 3 volumes of $15 \% 1 M$ formic acid-acetone prior to ion-exchange chromatography hastened the passage of the sample through the ion-exchange column and did not result in the loss of choline or internal standard.

Extraction of choline and internal standard from the dried ion-exchange eluate was quantitative if the salt residue was completely dry. Extraction was accomplished by washing the salt residue twice with $1 \mathrm{ml}$ of dry acetonitrile. The salt residue must be thoroughly scraped from the sides of the vessel and thoroughly mixed with the acetonitrile to ensure the quantitative removal of choline and internal standard.

The quantitative conversion of choline and internal standard to their 3,5dinitrobenzoyl esters required an excess of 3,5-dinitrobenzoyl chloride in dry pyridine but a nitrogen atmosphere was not required. Heating the samples with 3,5-dinitrobenzoyl chloride-pyridine at $105^{\circ}$ for an hour was found to afford the best results.

Quantitative extraction of dexivatized choline (DNB-choline) and internal standard (DNB-IS) from the residue that resulted after the removal of pyridine was effected with water. In order to ensure good peak heights in the HPLC chromatogram and to allow Millipore filtration of the sample, the total volume of water used in the extraction was critical. We extracted the residue first with $0.3 \mathrm{ml}$ water and then with $0.2 \mathrm{ml}$ water.

Separation of DNB-choline from DNB-IS could not be effected on a $\mu$ Bondapak analytical reversed-phase column without using a paired-ion. Use of $5 \mathrm{mM}$ sodium dodecyl sulfate in $50 \%$ acetonitrile afforded separation of the compounds (Fig. 1). The retention times for pure DNB-choline and pure DNB-IS were the same as the retention times observed when plasma samples containing the internal standard were processed and chromatographed.

The excess 3,5-dinitrobenzoyl chlozide required for the quantitative derivatization of choline and the internal standard was hydrolyzed to 3,5-dinitrobenzoic acid during the water extraction procedure. This acid eluted from the column as a massive peak at the void volume of the system. When a single reversed-phase column was employed, the DNB-choline and DNB-IS eluted on the tail of the 3,5-dinitrobenzoic acid peak. This situation was rectified through the use of two reversed-phase columns in series. The use of a flow-rate of 2.0$2.3 \mathrm{ml} / \mathrm{min}$ kept the peaks sharp and maintained separation of DNB-choline and DNB-IS.

Using the method of standard addition to a Red Cross human plasma pool, linearity was achieved from 1 to $500 \mathrm{nmole} / \mathrm{ml}$. Choline concentrations above 
500 nmole/ml afforded negative deviations from linearity. When ten identical plasma samples were analyzed by this procedure, the standard deviation was $\pm 6 \%$ of the mean.

\section{DISCUSSION}

In onder to test the effectiveness of our paired-ion HPLC choline assay, we used various plasma samples that we had stored in our laboratory freezer. These plesma samples were simultaneously analyzed by our HPLC procedure and by the gas chromatographic chemical demethylation procedure of Zahniser et al. [9]. The results are shown in Table I. The gas chromatographic procedure of

\section{TABLE I}

ANALYSES OF FUMAN PLASMA FRGM LITHUM-TREATED PATENTS VIA FPLC PROCEDURES AND GAS CHROMATOGRAPHIC PROCEDURES [3]

\begin{tabular}{lrr}
\hline Patient No. & HPLC choline (nmole/ml) & Gas chromatography choline (nmole/ml) \\
\hline 1 & 35.65 & 23.40 \\
2 & 21.82 & 5.54 \\
3 & 33.82 & 18.90 \\
4 & 16.00 & 15.60 \\
5 & 36.36 & 10.40 \\
$6(12 / 27 / 78)$ & 16.07 & 22.00 \\
$6(1 / 10 / 79)$ & 17.85 & 7.95 \\
7 & 21.38 & 15.10 \\
8 & 3.00 & 12.10 \\
9 & 7.56 & 17.50 \\
$10(1 / 4 / 79)$ & 25.78 & 21.00 \\
$10(1 / 11 / 79)$ & 23.11 & 12.20 \\
11 & 19.56 & 20.80 \\
12 & 10.22 & 13.00 \\
13 & 13.33 & 15.10 \\
14 & 20.89 & 11.30 \\
15 & 12.89 & 9.78 \\
Mean & & 14.80 \\
\hline
\end{tabular}

Zahniser et al. [9] does not utilize a true internal standand (the internal standard is added after precipitation of plasma protein), while our HPLC procedure does. This does not entirely explain the low values that were obtained. The use of sodium benzenethiolate for the demethylation of esterified choline via an $\mathrm{SN}_{2}$ mechanism, has been reported by Sheehan and Davis [16] to effect the base-catalyzed hydrolysis of the ester bond. This would result in low values of choline. Jenden and Hanin [8] reported that no cleavage of the ester bond took place in the chemical demethylation reaction, but they cosld not detect the presence of free choline by gas chromatography. Free choline is not volatile. Jenden and Hanin [8] instead looked for the presence of acetoxyethylphenyl sulfide which they did not find. Acetoxyphenylethyl sulfide would be formed if the benzenethiolate ion displaced the trimethylamino moiety. from choline via an $\mathrm{SH}_{2}$ mechanism but would not be formed if a base-catalyzed hydrolysis of the ester bond took place. In addition, any moisture present in 
the system would convert sodium benzenethiolate to benzenethiol which would not react with esterified choline but which would react with any oxygen that was present to form diphenyl disulfide. In essence, the amount of sodium benzenethiolate used in the gas chromatographic assay is critical and absolutely anhydrous conditions must be employed. The use of anhydrous conditions would not hinder the hydrolysis of esterified choline to free choline.

The plasma samples that were used to compare the HPLC assay with the gas chromatographic assay had been obtained from patients on long-term lithium therapy. The mean value that resulted from the gas chromatographic procedure for the fifteen samples that were analyzed, agreed very well with the mean plasma value, $14.9 \mu$ mole/1, reported by Jope et al. [20], who did not report the procedure for plasma choline analysis. The mean value for these samples when analyzed by the HPLC procedure was $36 \%$ higher.

\section{ACKNOWLEDGEMENTS}

The authors would like to thank Ms. Sandi Tait and Mr. Ben Mathews for the gas chromatographic analyses of the plasma choline samples.

\section{REFERENCES}

1 H: Baker, O. Frank, D.J. Tuma, A.J. Barak, M.F. Sorrell and S.H. Hutner, Amer. J. Nutr., 31 (1978) 532.

2 A.M. Goldberg and R.F. McCaman, in I. Hanin (Editor), Choline and Acetylcholine: Handbook of Chemical Assay Methods, Raven Press, New York, 1974, p. 47.

3 A.C. Kato, B. Colhir, D. Ilson and J. Wright, Can. J. Physiol. Pharmacol., 53 (1975) 1050.

4 S. Spector, A. Felix, G. Semenerk and J.P.M. Finberg, J. Neurochem., 30 (1978) 685.

5 S.-A. Eckermas and S.-M. Aquilonius, Acta Physiol. Scand., 100 (1977) 446.

6 S. Eksborg and B.A. Persson, in I. Hanin (Editor), Choline and Acetylcholine: Handbook of Chemical Assay Methods, Raven Press, New York, 1974, p. 181.

7 A.F. Maslova, in I. Hanin (Editor), Choline and Acetylcholine: Handbook of Chemical Assay Methods, Raven Press, New York, 1974, p. 215.

8 D.J. Jenden and I. Hanin, in I. Hanin (Editor), Choline and Acetglcholine: Handbook of Chemical Assay Methods, Raven Press, New York, 1974, p. 135.

9 N.R. Zahniser, D. Chou and I. Hanin, J. Pharmacol. Exp. Ther., 200 (1977) 545.

10 D.J. Jenden, M. Roch and F. Fainman, Life Sci., 23 (1978) 291.

11 I. Hanin and J. Sekerberth, J. Neuroch $\in$ m., 23 (1974) 819.

12 W.D. Lehmann, H.-R. Schulten and N. Schroder, Biomed. Mass Spectrom., 5 (1978) 591.

13 J.P. Green and P.I.A. Szilagyl, in I. Hanin (Editor), Choiline and Acetylcholine: Handbook of Chemical Assay Methods, Raven Press, New York, 1974, p. 151.

14 G.H. Posner and J.-S. Ting, Syn. Commun., 4 (1974) 355.

15 L. Fieser and M. Fieser, Reagents for Organic Synthesis, Vol. 1, Wiley-Interscience, New York, 1967, p. 1106.

16 J.C. Sheehan and G.D. Davis, Jr., J. Org. Chem., 29 (1964) 2006.

17 R.R. Renshaw, J. Amer. Chem. Soc., 32 (1919) 128.

18 V.d. Traynelis and J.G. Dadura, J. Org. Chem., 26 (1961) 686.

19 S.M. McElvain, Characterization of Organic Compounds, Macmillan, New York, 1961, p. 199.

20 R.S. Jope, D.d. Jenden, B.E. Ehrîch and J.M. Diamond, New Engl. J. Med., 299 (1978) 833. 